\title{
Prosthetic rehabilitation over implants in undergraduate education: removable prosthodontic, faculty of dentistry, unversity of concepcion, Chile
}

\begin{abstract}
Purpose: Removable Prosthodontic, Dental School, University of Concepción, with support of two suppliers of implants, from 2006 began a pilot undergraduate curriculum modification for teaching implantology and prosthetic rehabilitation making mandibular overdentures retained to two implants. This study describes the entire process of curricular modification.

Methods: 422 edentulous patients were rehabilitated with complete dentures for 422 year undergraduate students of the 4 years undergraduate 2007, 2008, 2009, 2010 and 2011, in Removable Prosthodontic, Dental School, Concepción University. Of the 422 patients, 97 patients with atrophic edges were selected to install Branemark implants (2007,2008 and 2009) and Zimmer implants (2010 and 2011) subsequently connected to mandibular overdentures. To ensure that all undergraduate students had the same experience, each course was organized annually in groups of four students, who participated in installation of implants and overdenture connection, tutored by faculties guide. Students and faculties guide were previously trained by specialists from the School in osseointegration and Prosthetic Rehabilitation on implants. In selected patients, prosthesis retention and the therapeutic satisfaction with them, was evaluated before and after installing the implants; connection to overdentures were made by students in Removable Prosthodontic. Opinion Survey was applied to students about this curricular experience.
\end{abstract}

Results: The results of measurements Prosthesis Retention and Satisfaction Therapeutics in patients, and the opinion of students, revealed statistically significant changes.

Conclusion: This results indicated the desirability of continuing the experience because it had a positive impact on the physical, mental and social well-being of selected patients, and attitude of students.

Keywords: overdenture undergraduate, satisfaction, overdenture retention, opinion students
Volume 9 Issue 6 - 2018

\author{
Alfonso Catalan, Francisco Marchesani, \\ Alejandra Martinez, Paulina Salazar, Daniela \\ Gonzalez, Felipe Burgos \\ Department of Dentistry, University of Concepción, Chile
}

Correspondence: Alfonso Catalan, Department of Dentistry University of Concepción, Roosevelt 1550, Concepcion, Chile, Tel 56-4I-220448I,

Email acetalan@udec.cl, juanalfonsacatalan@gmail.coom

Received: April 12, 2017 | Published: November 21, 2018

\section{Introduction}

Since the 1980s, in dentistry, the introduction of prosthetic rehabilitation on implants to restore full and partial edentulous increased progressively given the success and predictability of them . Hence, for the large number of complete denture wearing patients with difficulties in handling by poor preparation and severe atrophic ridges, rehabilitation with overdentures to implants, became the most important and reliable advancement and solution in dentistry .In therefore face this new reality, the new dentists must have a profile that includes these areas in their training. ${ }^{1,2}$ The use of osseointegrated implants according to studies of Branemark has allowed great therapeutic possibilities for patients with atrophic ridges. ${ }^{3}$ In addition overdentures retained to two implants offer for those efficient masticatory function, good retention and therapeutic satisfaction, with $95 \%$ success. ${ }^{4,5}$ The denture retention can be achieved with a variety of connection systems to those implants, of which the ball abutment with O-ring system would be the best evaluated. ${ }^{6,7}$ Satisfaction or comfort of patients with prostheses, expresses the degree of personal satisfaction in functionality, aesthetics, phonetics and sociability, and can be assessed with several different questionnaires described in the literature..$^{8-11}$

The Introduction of the teaching of rehabilitation on implants in dental curriculum has been undisputed, first in the graduate and then gradually in most undergraduate dental schools in the world. In USA $65 \%$ of the dental schools this was taught since 1985 in dental implantology level conferences. ${ }^{12}$ Later, in the 90 s, were published the first curriculum guides for teaching at the undergraduate implantology. ${ }^{13,14}$ In addition, early studies on implantology curriculum are published in almost all dental schools in North America, according to which $85 \%$ of them already included in the undergraduate implantology. ${ }^{15}$ Studies in 54 dental schools in the US revealed that $84 \%$ undergraduate students take a course in implantology and $16 \%$ haven't possibility because dental schools did not have to offer no such studies. ${ }^{16}$ Other studies in Europe in 56 dental schools in 33 countries, described that $75 \%$ of them requiring students to take courses in implantology. ${ }^{17}$ The courses were held on 4 th and 5 th year of the career with a duration of 4.2 months on average, with 11-50 hrs and $8 \mathrm{hrs}$ theoretical laboratory; $80 \%$ of faculties who lectured the courses were specialist in removable dentures; and $63 \%$ of students 
were required to attend surgeries and prosthetics that will connect the installed implants.

In Chile, 2009, the Program of Oral Rehabilitation mention Prosthesis Graduate, Faculty of Dentistry, applied a survey in 27 dental schools of differents universities in the country, which revealed that the curriculum in 26 dental schools did not consider teaching Implantology and Rehabilitation at the undergraduate level, and in only one of them was dictated. Although the Faculty of Dentistry in Chile increased by uncontrollable number and rapidly in recent years, very few have developed the theme of rehabilitation and implantology, in the Undergraduate area, although students show great interest in having a contact with this subject in a theoretical and practical level basic earlier in the curriculum. Currently, compulsory curriculum in 38 schools of the country have not yet considered the teaching of implantology in theoretical and clinical form at the undergraduate, according to information presented on their websites; only a faculty continues proving practical and theoretical contentsin prosthetic rehabilitation clinic and implantology in the course of Removable Prosthetics. ${ }^{18}$

In this study, the experience of Prosthesis Removable discipline of the Faculty of Dentistry is described. This Faculty dictates theoretical and practical content progressively distributed in the curriculum, and clinical activity in the Removable prosthetic rehabilitation retained to two implants, to level 4th and 5th year of Dentistry as a mandatory requirement from 2007 to the present.

The aims of this study were:

1. Determine the average annual edentulous patients with mandibular edges not candidate for retaining prosthesis Removable Prosthesis, Faculty of Dentistry.

2. To enable undergraduate students of Dentistry in overdentures retained to two implants, rehabilitating edentulous patients with severe atrophic mandibular ridges.

In patient selected for implants of years 2008 to 2012, to evaluate the retention and patient therapeutic satisfaction with implantretained dentures with early loading, before and after connecting to the implants. Evaluate the teaching model undergraduate Prosthetic Rehabilitation with overdentures retained to two implants, Removable Prosthetics School of Dentistry, with the opinion of undergraduate students on applied experience.

\section{Material and methods}

This study was approved by the Ethics Committee.

To determine the percentage of patients with unfavorable and atrophic edge of total edentulous who attend annually Clinical RemovableProsthetics were considered and evaluated all patients rehabilitated with conventional complete dentures without implants from 2008 to 2012. Clinical examination of their treatments according to clinical charts included, evaluation of stability and retention of prosthesis, Vertical Dimension, Centric occlusion, balanced occlusion, use of prostheses and classification of edge. The total of 422 students dentistryof Removable prosthesis who were: 91 (2008), 81 (2009), 89 (2010), 78 (2011) and 83 (2012), in Prosthesis Removable received clinical theoretical contents of osseointegration, implant surgery and prosthetic rehabilitation on implants.In addition, they attended preclinical surgical and prosthetic rehabilitation on implants, taught by Implantology and Rehabilitation faculties and supported by Nobel Biocare material and ZIMMER material; each student in fourth year performed prosthetic rehabilitation of edentulous patient bimaxillary to the insertion and termination (subject requirement at Removable Prosthesis); and as there was no patient Overdenture for each student, the total course was organized in groups of 4 students each to participate in the installation of implant surgeries in selected patients; later, in the fifth year the same groups of students performed the connection of the prosthesis to the implants; all clinical actions were supervised by Removable Prosthetics and implantology faculty professors. This academics were trained previously with theoretical clinical course prosthetic rehabilitation and implants.

\section{Patients}

From Total of 422 patientscomplete dentures wearers considered, 97 patients (18 in 2008, 23 in 2009 and 18 of 2010 patients, 21 of 2011 and 17 of 2012) with the atrophic ridges were selected to install implants, according to inclusion and exclusion international criteria (Table 1). The Complete denture rehabilitations of all patients including those selected for implants were performed by four year students in the fourth year as part of their regular requirements in Prosthesis Removable clinic under supervision of their faculty. Informed consent was requested of the patients selected to install implants. Every clinical course, at the level of the fourth year, was organized in teams of four students to participate in surgery implants placement in Overdenture patient selected. The placement of implants was performed with early loading by the implant surgeon helped by students in each team. The Implants were MK3 and MK4 Nobel Biocare and TSVB MTX surface Zimmer. Abutments type sphere were used for all implants; and connections were made with gold cap for Branemark implants and housing cap for implantZimmer. The Implants were installed with torque for early loading were Biocare Implants: 36 (2008), 46 (2009) and 36 (2010); and Zimmer: 42 (2011) and 34 (2012). Later, during the fifth year of dentistry, clinical Removable Prosthetics, the same team of students performed controls and connection of these implants to overdenture, supervised by the removable prosthetic faculty.

Table 1 Patients selected for overdentures retained to two conventional implants

\begin{tabular}{lllllll}
\hline Year & 2008 & 2009 & 2010 & 2011 & 2012 & total \\
\hline Total students & 91 & 81 & 89 & 78 & 83 & 422 \\
Total patients & 91 & 81 & 89 & 78 & 83 & 422 \\
Patients Selected & FOR 18 & 23 & 18 & 21 & 17 & 97
\end{tabular}

\section{Retention and therapeutic satisfaction evaluation}

\section{Retention}

Retention overdenture to the implants was measured with a digital dynamometer (Lutron Digital Force Gauge; Lutron Electronic Enterprise Co., Ltd., Washington, DC). A stainless steel hook was located in the middle of the lingual edge of the denture, and the other end was connected to a dynamometer. Retention overdentures was measured before placing the implants and again at 1 and 3 months after implant placement. The average of three retention measurements of the dentures to the implants was recorded at each of the observed time points.All measurements were obtained from all selected patients. ${ }^{19}$

\section{Therapeutic satisfaction}

In the same session, the therapeutic satisfaction survey of the University of Concepcion's Faculty of Dentistry's Oral Prosthetic Rehabilitation Program Graduate was applied at different stages. ${ }^{19}$ 
The survey consisted of 19 questions. Question 10 assessed the chewing ability of patients with 13 specific foods. Each food received an individual score. The following items were included on the patient survey: frequency or use of the prostheses; comfort level; denture retention; denture stability during opening; denture stability and retention during speaking; denture retention and stability while chewing; the presence of "clack" sounds while speaking; the presence of pain; the presence of check-biting; limitations on individual diets; the degree of difficulty while eating bread, toast, cheese, lettuce, boiled potatoes, roasted vegetables, raw carrots, apples, walnuts, almonds, peanuts, roasted chicken, or chocolate; the presence of masticatory muscular fatigue, difficulty in swallowing, esthetic appearance; social interactions and individual mood; and finally the influence on their quality of life. Each item was assigned an individual score, ranging from 0 (worst) to 4 (best), and thereby the sum of the individual scores resulted in the total level of therapeutic patient satisfaction (Table 2).${ }^{19}$ The Student opinion about the experience or curricular modality in which participated was obtained with a survey view 17 items, of which 5 items were considered to present the trend of opinion.

Table 2 Therapeutic satisfaction ranges

\begin{tabular}{ll} 
Therapeutic satisfaction & ranges \\
\hline Very poor & 0 to 73 \\
Poor & 74 to 100 \\
Good & 101 to 127 \\
Very good & 128 to 148
\end{tabular}

Thisanonymous survey included the following items:

Question 1: Are you interested in the subject of rehabilitation and implantology?

Question 2: How do youevaluateyourself in terms of knowledge on rehabilitation and implantology?

Question 3: How teaching of implantology and rehabilitation should be?

Question 4: At what time the delivery of theoretical-practical knowledge should be?

Question 5: How important do you consider the curricular applied experience?

Statistical Analysis of all the results was performed using the Student test for satisfaction survey, and with the Friedman test for measurements of retentions.

\section{Results}

\section{Total patients wearers before selection for Overdentures}

To determine the clinical characteristics of mandibular edges and wear of conventional dentures without implants, when patients applied for their new rehabilitation, a total of 422 patients wearers (91 (2008), 81 (2009), 89 (2010), 78 (2011) 83 (2012) ) were evaluate. The clinical characteristics of mandibular ridges were favorable in $34 \%$ of patients and unfavorable in $66 \%$ of patients (Figure 1). Percentage of permanentwear in 422 patients complete denturewearerswere $87 \%$ for Permanent wear and $3 \%$ non wear (Figure 1). The retention of the conventional mandibular prostheses without implants revealed to bad in $58 \%$ of the cases and good and regular in $42 \%$ (Figure 1). The therapeutic satisfaction with their conventional prostheses without implants was unsatisfactory in $29 \%$ of the cases, and satisfactory or very satisfactory in $71 \%$ (Figure 2 ).

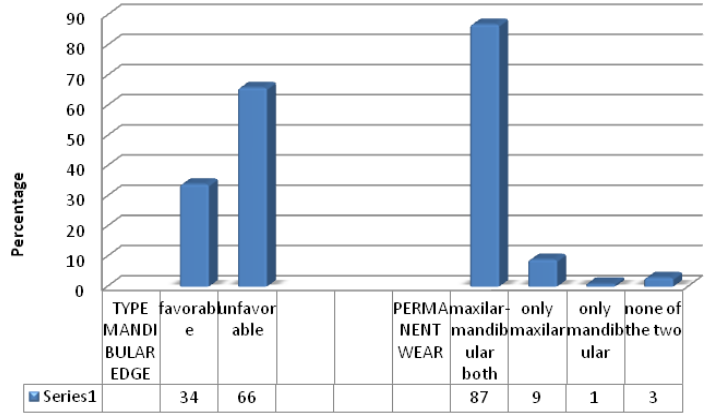

Figure 1 Characterics of mandibular edges patients and permanent wear complete denture in total of 422 patients weares before selection for overdentures implant retained from 2008,2009, 20102011 and 2012 years

80

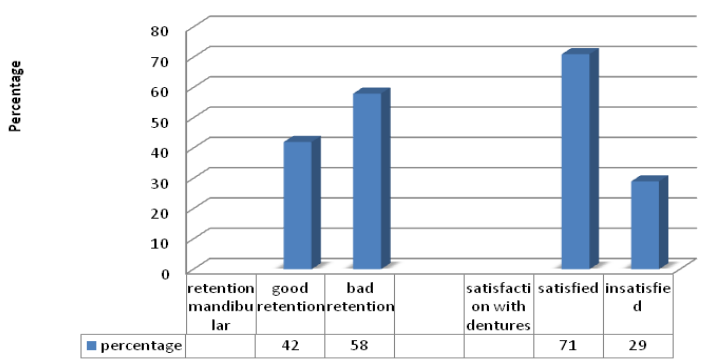

Figure 2 Retention mandibular denture and Therapeutic satisfaction with denture in 422 patients complete dentures wearers before selection for overdentures implant retained from 2008, 2009, 2010, 2011 and 2012 years.

\section{Patients selected with overdentures connected to implants}

Of the 422 patients rehabilitated, a total of 97 patients ( 18 in 2008, 23 patients in 2009, 18 in 2010, 21 patients in 2011 and 17 in 2012) were selected for implant installation and connecting to mandibular overdenture (Table 1). In the group of patients with overdentures, retention to the implants revealed the following average values per year expressed in newton, (Figure 3). Newton retention measured before installing implants had a PM of 0.06 Newton, with a minimum value of 0.03 Newton and a maximum of 0.18 Newton.

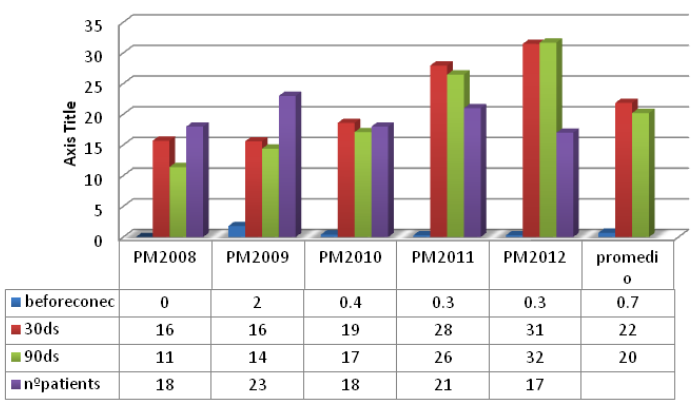

Figure 3 Retention of mandibular overdentures connected to two conventional implants Branemark (2008,2009 and 2010) and Zimmer(2011 and 2012) in 97 patients selected before and after connection.

Retention measured after one month of installation and when the implants were connected was a PM of 22 Newton, with a minimum of 1 Newton and a maximum of 32 Newton (Figure 3). Results of 
the therapeutic satisfaction in the 97 patients with overdentures retained to two implants before and until 3 months after the implants were installed and connected, the following average values per year are revealed, (Figure 4). The therapeutic satisfaction in score after installing the implants was BAD with a PM of minimum value of 76 and a maximum of 110 . The therapeutic satisfaction assessed at one month after the implants were installed and connected was GOOD and VERY GOOD, with a PM of 130, a minimum value of 128 and a maximum of 131 (Figure 4). The therapeutic satisfaction assessed at three months after the implants were installed and connected was GOOD and VERY GOOD, with a PM of 132, a minimum value of 120 and a maximum of 133 (Figure 4). The Therapeutic Satisfaction for the patients Branemark system $(2008,2009,2010)$ and patients Zimmer system $(2011,2012)$ were similar and no different statistically significant.

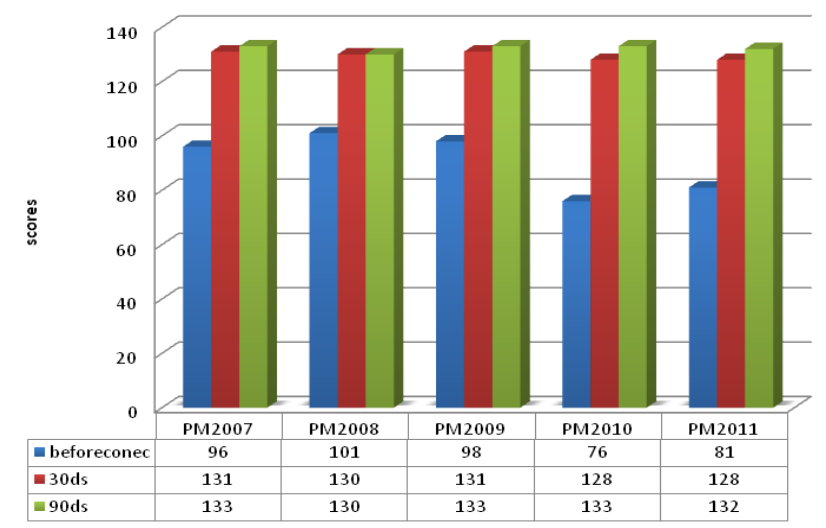

Figure 4 Therapeutic satisfaction in the 97 patients with overdentures retained to two implants (Branemrk 2008, 2009, 2010; Zimmer, 2011, 2012) before and until 3 months after the implants connection.

Opinion of the undergraduate students on experience of overdentures

The opinion survey of the students to this experience according five question selected reveals the following results:

Question 1: Are you interested in the subject of rehabilitation and implantology?

Yes, they are very interesting $=98 \%$; No, they are not interested $=2 \%$; No answer $=2 \%$

Question 2: How do youevaluateyourself in terms of knowledge on rehabilitation and implantology?

Only Have read, non applicable $=82 \%$; could apply $=13 \%$; do not know $=5 \%$

Question 3: How teaching of implantology and rehabilitation should be?

Elective subject $=3 \%$, independent subject $=42 \%$; compulsory content in curriculum $=54 \%$

Question 4: At what time the delivery of theoretical-practical knowledge should be?

Beginning carrer $=2 \%$; only clinical courses $=29 \%$; progressively from 1 rst to $5^{\text {th }}=69 \%$

Question 5: How important do you consider this curricular applied experience?

Yes, very important $=90 \% ;$ not $=8 \%$ no answer $=2 \%$

\section{Discussion}

A total of 422 patients carriers were examined prior to both rehabilitation and installation of implants. Of these, $66 \%$ have unfavorable edges and $58 \%$ of these patients have a deficient retention of their prostheses. TABLE 1 . These values are lower than those in other Studies..$^{20,21}$

Despite that only $29 \%$ of the patients examined are unsatisfied with their prostheses, $71 \%$ of the same patients is revealed satisfied or very satisfied with their prostheses. Fig 1 . This percentage differs from the high rate of dissatisfaction of patients with conventional prostheses showed by other Studies. ${ }^{20,21}$ However, results of this study indicate that $85 \%$ of the patients used both prostheses.

Dissatisfaction would be related to this lack of retention, according to other authors. ${ }^{21}$ Later, in the 93 patients selected for implants, retention of the mandibular prostheses significantlyincreased when connected them with implants with average values of $1.64 \mathrm{kgrs}$ (Figure 3).

Retention to traction obtained in this study for the mandibular overdentures before connecting them to the implants was PM of 0.55 $\mathrm{N}(0.25 \mathrm{~N}$ in the lowest and 0.74 in the highest retention), and after the connection the overdentures with ball pillar resistance to traction, increased to a PM of $17.5 \mathrm{~N}$ (30.4\% the highest resistance and 11.6 $\mathrm{N}$ in the lowest) (Figure 3). These results are highly significant, they appeared in $100 \%$ of the patients, they are consistent with the literature, and they are within the expected range and described by other authors. ${ }^{910,18,19,22,23}$ In the same patients, in this study, the therapeutic satisfaction increased significantly, with previous values to the connection of PM 90 points (poor or bad), a PM 130 points (satisfactory or very satisfactory), post connection prosthesis implant (Figure 4).

Satisfaction scores obtained in this study are significantly higher in the treatment with mandibular overdentures retained with two implants compared to conventional treatment with maxillary removable dentures. There is evolution from the beginning as unsatisfactory and unsatisfying Therapeutics Satisfaction, 30 days pass inserted prostheses acceptable and satisfactory, and subsequently connected to the implants prostheses passed to a category of very satisfactory (Figure 4). These results are consistent with other studies, patients with other numbers, different age groups, different types of connections and different types of surveys to measure the level of patient satisfaction, but can be comparable because they involve similar parámeter ${ }^{5,7,10,24,25}$ Another study comparing satisfaction before and after prosthesis implant connection with ball abutment and locator, saw significant differences for both $^{7}$ also consistent with this investigation. Other results that compared Therapeutics Patient satisfaction among conventional prostheses and overdentures describe significant differences between the variables, independent of the type of survey utilizado, findings are also consistent with the present study. ${ }^{24,26,27}$ The opinion of students regarding the compulsory curriculum change is highly favorable and significant. They say that in front Question 2, only they have read; and about question 1, Yes, they are very interesting. And the teaching of implantology and rehabilitation must be compulsorycontent in curriculum (question 3 ) and progressively from 1 rst to $5^{\text {th }}$ (question 4$)$. Then, it is very important consider the this curricular applied experience (question 5). 


\section{Conclusion}

$85 \%$ of all patients rehabilitated at the Faculty wearing both types of permanent prosthesis, despite the unfavorable condition of his atrophic edges. Patients rehabilitated with implants reveal a therapeutic retention and satisfaction with their highly significant prosthesis in the observed periods. Undergraduate students who participated in the modality expressed an opinion and favorable disposition to consolidate this change and extend it to other rehabilitation disciplines. Compulsory implant rehabilitation activity in the undergraduate is very positive in the academic and social aspect.

\section{Acknowledgements}

None.

\section{Conflict of interest}

The author declares that there is no conflict of interest.

\section{References}

1. Emami E, Heydecke G, Rompre PH, et al. Impact of implant support for mandibular dentures onsatisfaction, oral and general health related quality of life: A meta-analysis of randomized-controlled trials. Clin Oral Implants Res. 2009;20:533-534.

2. Fontijn-Tekamp FA, Slagter AP, Van der Bilt A, et al. Biting and chewing in overdentures, full dentures and natural dentitions. $J$ Dent Res. 2000;7:1519-1524.

3. Mish CE. Implantología contemporánea. España: Elsevier;2009:8-16.

4. Attard N, Diacono M. Early loading of fixture original implants with mandibular overdenture a preliminary report on a prospective study. Int J Prosthodont. 2010;23(6):507-512.

5. Sadowsky SJ. Mandibular implant-retained overdentures: A literature review. J Prosthet Dent. 2001;86(5):468-473.

6. Tokuhisa M, Matsushita Y, Koyano K. In vitro study of mandibular implant overdenture retained with ball, magneto, or barattachments: Comparison of load transfer and denture stability. Int J Prosthodont. 2003;16(2):128-134.

7. Geckili O, Hakan B, Tayfun B. Locator attachments as an alternative to ball attachments in two implant retained mandibular overdentures. $J$ Can Dent Assoc. 2007;73(8):691-694.

8. Strassburger C, Heydecke G, Kerschbaum T. Influence of prosthetic and implant therapy on satisfaction and quality of life:A systematic literature review. Part 1-Characteristic of the studies. Int J Prosthodont. 2004;17(1):83-93.

9. Sadig W. A comparative in vitro study on the retention andstability of implant supported overdentures. Quintessence Int. 2009; 40(4):313-319.

10. Vega D. Evaluación de sobredentaduras mandibulares implantoretenidas confeccionadas con técnica Rehabilitación Oral M/Prótesis, Facultad Odontología, Universidad de Concepción, en pacientes del Servicio Salud Bío-BíoEvaluation of mandibular overdenture implant retained made with Oral Rehabilitation Prosthetic mention Technique from Faculty of Dentistry, University of Concepción, in patients Health Service Bío Bío. Revista Clínica de Periodoncia, Implantología y
Rehabilitación Oral. 2015;8(2):117-123.

11. Boretti G, Bickel M, Geering AH. A review of masticatory ability and efficiency. J Prosthet Dent. 1995;74(4):400-403.

12. Arbree NS, Chapman RJ. Implant education program in north american dental school. J Dent Educ. 1991;55(6):378-380.

13. Simons AM, Badr SE. Pre-doctoral education in implant dentistry: curriculum guidelines. J Mich Dent Assoc. 1990;72(10):469-470.

14. Curriculum guidelines for predoctoral implant Dentistry. J Dent Educ. 1991;55(11):751-753.

15. Weintraub AM, Seckinger R, Berthold $P$, et al. Predoctoral implant dentistry program in US dental school. J Prosthodont. 1995;4(2):116-121.

16. Lim MV, Afsharzand Z, Rashedi B, et al. Predoctoral implant education in usa dental schools. J Prosthodontics. 2005;14(1):46-56.

17. Afsharzand Z, Lim MV, Rasheidi B, et al. Predoctoral implant dentistry curriculum survey: European dent schools. Eu J Dent Educ. 2005;9(1):37-45.

18. Catalán A, Marchesani F, Martínez A. Prosthetic Rehabilitation Over Implants in Undergraduate Education, Removable Prosthodontic, University of Concepcion, Chile. The 2ndFutureTrends in Implantology. Internat Dental Conference. Florenze Italy. 2010;11(13).

19. Catalan A, Martinez A, Marchesani F, et al. Mandibular Overdentures Retained by Two Mini-Implants:A Seven-Year Retention and Satisfaction Study. J Prosthodontics. 2016;25(5):364-370.

20. Bilhan H, Geckili O, Ergin S, et al. Evaluation of satisfaction and complications in patients with existing complete dentures. J Oral Sci. 2013;55(1):29-37.

21. Gosavi SS, Ghanchi M, Malik SA, et al. A survey of complete denture patients experiencing difficulties with their prostheses. J Contemp Dent Pract. 2013;14(3):524-527.

22. Thomason JM, Kelly SA, Bendkowski A, et al. Two implant retained overdentures: A review of the literature supporting theMcGill and York consensus statements. J Dent. 2012;40(1):22-34.

23. Orellana B, Catalan A, Vargas A, et al. Evaluación de sobredentaduras mandibulares implanto-retenidas confeccionadas con técnica Rehabilitación Oral M/Prótesis, Facultad Odontología, Universidad de Concepción, en pacientes del Servicio Salud Bío-Bío. Rev Clin Periodoncia Implantol Rehabil Oral. 2015;8(2):117-123.

24. Preoteasa E, Marin M, Imre M, et al. Patients' satisfaction with conventional dentures and mini implant anchored overdentures. Rev Med Chir Soc Med Nat Iasi. 2012;116(1):310-316.

25. Van der Bilt A, Van Kampen FM, Cune MS. Masticatory function with mandibular implant-supported overdentures fitted with different attachment types. Euro J Oral Sci. 2006;114(3):191-196.

26. Cheng T, Sun G, Huo J, et al. Patient satisfaction and masticatory efficiency of single implant-retained mandibular overdentures using the study and magnetic attachments. J Dent. 2012;40(11):1018-1023.

27. Ortegón SM, Thompson GA, Agar JR, et al. Retention forces of spherical attachments as a function of implant and matrix angulation in mandibular overdenture: An in vitro study. J Prosthet Dent. 2009;101(4): 231-238. 